\section{Quod Erat Expectandum: The \\ Modus Operandi of Models and Quantifications}

GI_Forum 2018, Issue.1

Page: 274 - 290

Full Paper

Corresponding Author:

andreas.koch@sbg.ac.at

DOI: 10.1553/giscience2018_01_s274

\author{
Andreas Koch \\ University of Salzburg, Austria
}

\begin{abstract}
Models and quantitative analyses deal with numbers. In general, numbers have a very specific meaning in that they represent a phenomenon as idiosyncratic (singular) in a way that words cannot do. However, the quality as well as the quantity of a phenomenon must be considered in order to understand its nature more comprehensively. Furthermore, the use of both numbers and terms incorporates presuppositions about what is perceived as relevant and valuable, which is not usually evidently visible - their existence is realized through reductionism. The reduction of a phenomenon to a number, therefore, does not neglect its intrinsic value. As is the case with terms, models and quantities are jeopardized by being instrumentalized in scientific research and political debates. 'Quod erat expectandum' thus has a twofold meaning: (i) Models and quantifications are expected to create a reality rather than simply represent it. They are used to grasp the world(s) that surround(s) us. (ii) Models and quantifications are expected to reduce complexity. This methodologically and epistemologically built-in mechanism is - in a positive as well as in a critical sense - inevitable.
\end{abstract}

\title{
Keywords:
}

singularity of numbers, framed analysis, reductionism, models as creators of realities

\section{Introduction}

'Impossible is something that does contradict to be. Possible is something that does not contradict to be. Accidental is something that does not contradict not to be. Necessary is something that does contradict not to be' (Kamper, 1996: 109; translation A.K.). This interplay suitably frames the intention of this paper. The circularity of semantic associations is a presupposition that helps us to comprehend coherently each sentence and the relationships of all four sentences to each other. Be it theories or methods, descriptions or explanations, texts or maps, relationships always create, explicitly or implicitly, these nexus with which particularities are contextualized. Contextualization generates meaning. However, neither the creation of relationships nor the creation of meaning is founded on objective criteria - not in science and not in everyday life. They are not, on the other hand, completely 
arbitrary, but depend on particular social-cultural, temporal (historical) and spatial (geographical) contexts.

The referential contexts emphasize in addition that how and why complementarities are fundamental for comprehensive reasoning. Complementarities can be dialectic; the decisive point is that they simultaneously express a mutual excluding and complementing relationship, as is the case of the dualism between wave and particle, or of impulse and location in physics. One characteristic of complementarity is that the so-far unconnected (or differently connected) components do already exist. Every social construction of space, for instance, presupposes spatial rules, patterns and conventions which are independent properties compared with the social rules, patterns and conventions that are applied when taking possession of social space. We can find this complementary also in geometry, topology or algorithmic computation. This is equally true for every statistical analysis. The result of a model run or a statistical analysis assumes the selection of one or more techniques which themselves are based on concrete procedural rules (e.g. that interactions among agents, and between agents and their environment are taken into consideration). The process of computing a number is usually not reflected in the result, unless it is made explicit. In this respect, a mathematical emergence of reality does not differ from a textual or a (cartographical one: in all cases we refer to a priori objectives, reflections, etc. Their difference lies in the nature of translation.

To model geographical phenomena from a social scientific perspective, an understanding of relations and complementarities is crucial, because both spatial and social facts rely heavily on their inner-temporal dynamics and develop differently over time (see also Schäfer and Schnelle, 2012, pp. xx-xxi). Social-spatial segregation processes may obey common rules of homogenization. The quality of the process, however, and its concrete manifestations in social, cultural and architectural upgrading (gentrification) are influenced by the idiosyncratic peculiarity of their local, temporal and community compositions.

These introductory remarks aim at highlighting the relevance of relationship, reference and complementarity in understanding our world scientifically as well as from a Lebenswelt perspective. In the remainder of this paper, this world comprehension will be discussed from a model-theoretical perspective and a quantitative-methodological one (the latter including analytical methods), focusing exemplarily on the social-geographical phenomena of regional disparities, social inequality and poverty, and processes of segregation. In so doing, it takes into consideration the work of an increasing number of GIS experts on these social-scientific issues within the field of geographic inquiry. From an epistemological point of view, we should emphasize the link between model theory and quantitative methods: numbers, and thus their peculiarities, are used in both quantitative analytical methods and the models discussed here. Furthermore, analytical methods such as multivariate regression or cluster analysis produce and use models in the same way as simulation modelling.

\section{Some peculiarities of the quantitative approach}

According to Lewin (1931), three approaches to accessing reality can be distinguished: the Homeric mode of narration, which gives priority to moral judgements; the Aristotelian mode 
of classified descriptions, which focuses on differentiation (e.g. dark-light); and the Galileian approach to measuring, which stresses exactness. In addition, one could refer to the Ortelian approach to cartography, which offers a synchronous representation of recognition (the English word 'recognition' refers to cognition ('erkennen' in German) and recognition ('anerkennen' in German), thus the complementary referencing mentioned above). From a practical perspective, it is important to recognize that all four different approaches and the mutual transitions between them are crucial when reasoning about reality. No access to reality is restricted exclusively to one single approach or mode.

In contrast to the common understanding of quantities which are assumed to devalue the individual as an abstract number and negating the individual's qualities, Lewin (1931: 150) appreciates the peculiarity of quantification: 'It is the increased desire, and also the increased ability, to comprehend concrete particular cases, and to comprehend them fully, which, together with the idea of the homogeneity of the physical world and that of the continuity of the properties of its objects, constituted the main impulse to the increasing quantification of physics.' Numbers, quantifications and their emergence through quantitative methods are one possibility to attribute a kind of uniqueness to facts, phenomena and events which cannot be realized by the other approaches. 'There is nothing more abstract and singular than numbers. Beyond numbers no further abstraction is thinkable, because abstracting from numbers would mean to disregard singularity. This in turn would mean to give up the Self, because the Self is only possible in contradistinction to "Another" (Weiss, 2010: 4; translation A.K.). Interestingly, the concept of singularity has gained increased attention in contemporary sociological thinking (see Reckwitz (2017) and Rosanvallon (2013)). Weiss also points out that quantity (the single part) and quality (the whole) conflate; they can be distinguished analytically, but need to be mutually related in order to understand both sides of the coin - and the coin.

The complementarity of quantity and quality, of quantification and qualification, is realized through translation, and this procedure must be recalled when statements and numbers as well as their manifold representations are captured and utilized. Detractors of quantification tend to create an asymmetry between the two worlds. They argue that if a qualitative phenomenon is being tied to a number, it will lose its intrinsic value - the only thing that counts henceforth is its numerical value. The processes and mechanisms of its creation, and their cultural, geographical or temporal differences remain opaque (Mau, 2017: 61). Although this problem definitely exists, it is not a problem of the quantification itself but one of exposing the cultural, political, social and scientific circumstances of its creation. The use of numbers and words therefore incorporates presuppositions about what is perceived as relevant and valuable.

\section{Implications of applying analytical methods, numbers and models}

As a preliminary conclusion we can say that quantitative approaches in social-spatial investigations are relevant as well, because they specifically make relations visible and comparable. By referring to scalable domains, they move beyond material and metaphorical characteristics of space and society. Attempts to define regional disparities may be a good 
example of dealing with quantities qualitatively. Maretzke (2006: 473) proposes a definition of regional disparities as 'deviations of particular indicators which are assumed to be relevant, from an imagined reference distribution [...], which is being related to a particular spatial scale, depending on the subject matter' (translation A.K.). Measuring deviations depends fundamentally on available instruments and data. Crucial, however, is the problem at hand. The problem in turn is interrelated with theoretical, empirical, normative and experimental issues, and should not primarily be determined by questions of data acquisition.

Commonly, a pragmatic compromise of theoretical, methodological and applied justifications must be realized in scientific and political praxis. This, however, should not induce an attitude that attributes a law-like status to the compromise. Nor should the problem be adapted to the methodological 'needs'. The transparency and reproducibility of the research process give numbers and models their value. With regard to spatially referenced comparisons, Belina and Miggelbrink (2010: 14) require that 'the reasons for the creation of entities and references of comparisons be unfolded. Neglecting this implies a production or confirmation of ideologies by corroborating comparisons with seemingly objective statements about seemingly self-evident entities' (translation A.K.). These are reasonable requirements, because experience, familiarity and persuasion for or against a method, technique or model are characteristics of a research process. What may grow as an independent force can be termed 'voiceless knowledge' (Rheinberger, 2001: 80).

Measurements, quantifications and models allow the emergence of a concrete single case, as argued above. What they convey must be contextualized; from an epistemological perspective, this contextualization is the well-known three-fold 'context of discovery', 'context of justification' and 'context of utilization'. In addition, contextualization must refer to other measurements and models in order to validate model results, but also to utilize them comparatively in connection with other approaches (see Christie et al., 2011: 5). This approach is not a competition between outcomes and paradigmatic settings but an abductive approach to the explicit problem(s) at hand.

This may sound trivial. Indeed, the claim for transformability (of methodological approaches, of modelling aims and types, etc.) among and between modelling paradigms, and scientific and epistemological explanations has been voiced many times over the past six decades or so. One of the voices was that of Ludwik Fleck, a Polish physician who refused to accept an 'absolute truth' as an epistemological counterpart of scientific exploration. He insisted on three social factors which inherently determine scientific reasoning (Schäfer and Schnelle (2012: xxii) in their introduction to the life and work of Ludwik Fleck):

(1) The 'weight of education': knowledge consists foremost of learnt items, being then subtly transformed by learning and communication.

(2) The 'burden of tradition': new recognition is coined primarily by already existing recognition.

(3) The 'effect of the recognition sequence': what has once been conceptualized theoretically and/or methodologically limits the creation of new concepts.

Incorporating these social factors into the evaluation of research results may help to focus less on unobtainable truths and more strictly on the processes and purposes of model production. 


\section{$4 \quad$ Model purpose and circularity within the quantitative approach}

Measuring and modelling regional disparities become more important if they coherently unfold the selection of 'indicators which are assumed to be relevant'. This implies integrating the quality of the indicators, as a complement to their quantitative manifestation. Qualities, too, need referencing to a spatial, temporal and social scale. The qualitative experience of inequality feeds mainly on very subjective and local living conditions; however, it is simultaneously an amalgamation of aggregated knowledge as 'socialized subjectivity' (see Bourdieu and Wacquant, 1996: 159). This kind of knowledge, which refers to local and subjective-social living conditions, can be termed 'local knowledge'. Though deriving from a different epistemology and perspective (ethnography and indigenous populations in developing countries; see Geertz, 1993), local knowledge can be transferred to contemporary (post)modern, globalized and localized living conditions as well. Local knowledge of people living in impoverished or wealthy regions is important for disparity research, not just for scaling, because it incorporates another mode of observation. While in scientific and political contexts knowledge about poverty, inequality or disparate living conditions is mostly a perspective of people who are not affected by these disparities (a second-order observation), local knowledge of poor and excluded people offers a first-order observation which can be derived at least in part from participatory fieldwork and interviews (Koch, 2013).

In addition to mutual relationships between different modes of recognition, ordering and understanding, it is important to account for the relationships within the quantitative methodology. It can be confirmed that 'calculating brings into being equality of opportunity' (Lotter, 2011: 43), because inequality can - and must - be made comparable through exact differentiation and objectivation which can then be used for opinion-forming in the political arena. Regionally varying patterns of the allocation of goods and services are usually approached by economic indicators such as business sectors, public infrastructures and economic innovation. These indicators provide a reference for evaluating the legal mission of creating, improving and/or preserving equivalent living conditions. As long as statistical analyses are considered one instrument among others, I would agree with Lotter. If not, 'equality of opportunity' may become a misuse of ideology, representing an interest- and power-driven inequality of opportunity, since there is no longer any explicitly proposed reduction of complexity. This is why Strubelt (2006: 307) claims: 'Thus, equivalence [of living conditions] nowadays has changed its meaning. As an abstract aim, and independent of difficulties of measuring and illustrating disparities [...], it has become a conceptual and political idea which is hard to operationalize. Attempts to solve this by applying very different indicators and by creating rankings of regions [...] attract high public interest, but are methodologically very problematic. They often represent a trivial reduction of complexity [...]' (translation A.K.).

A reduction of complexity is an inevitable step in perceiving and grasping our world. It is, however, simultaneously necessary to deal with this reduction of complexity in an explicit and deliberate fashion. To make 'explicit' means to publish not only the results of an analysis but also the process of its realization; 'deliberate' means to examine the chosen method(s) critically. (See, e.g., Cremer (2016: 19-26) for his detailed description of the creation of the 
'risk of poverty threshold' and its implications, and Lepenies' (2017: 65-80) delineation of measuring poverty in London in the 19th and 20th centuries.)

Another problem of the internal confirmatory referencing of quantitative methods is the danger of making absolute not only the values measured but also the models and techniques applied. The mathematician Ortlieb calls this 'to explain the real through the impossible' and exemplifies it for economics: 'Economics creates mathematical models which never could be rebuilt in reality but are used nevertheless to compute and reduce complex economic processes to a few numbers. Here, too, models and numbers try to describe the real through the impossible. [...] Neoclassical economics assumes a kind of market harmony. If markets are left to their own devices, then everything develops best. Dummy arguments are used to confirm this opinion by misusing mathematics in order to promote ideology' (Link, 2001: 112-13; this quotation is based on an interview with Ortlieb; translation A.K). The critical point is not that quantitative methods deal with artificial experimental settings or models, but that they immediately equate models with reality. Rather, models - through their construction and focus - create a reality through their use in science and everyday life (this is explained in more detail in the next section). In addition, methodological and technological progress must be thought of explicitly too. Batty (1995: 16) emphasized this with respect to the development of Geographical Information Systems (GIS) at that time: 'TT]he current generation of GIS are systems which are not well adapted to their context, contain little of the theories and methods which have been developed over the last two decades in subject areas embracing the spatial perspective, and rarely focus upon the particular characteristics of the problems to which they are being addressed.'

\section{$5 \quad$ Reductionism and scaled circularity}

For an appropriate appreciation of quantification and modelling, a different kind of conclusive translation between method and epistemology seems to be necessary. Statistics often assumes an absence of ideologies and normative values, which is not true when we consider the modes of acquiring, producing and publishing data and results. The basic instruments with which we observe, describe, explain and interpret the world are models there is no immediate access to our spatial and social environment.

This must be briefly explained. I agree with Schurz (2008: 56-57) who argues for a hypothetical-constructivist realism approach. According to this realism, our perception and imagination of reality are not given a priori, but constructed and conditioned through active cognition (which is referred to as 'epistemic constructivism'). Contrary to an ontological constructivism which argues conclusively that reality, too, is not given a priori, hypotheticalconstructivist realism does not link perception and reality as closely. Instead, it assumes a structural correspondence which transforms information between perception and reality, and this transformation is neither complete nor unambiguous. Taking such a corresponding linkage into consideration leads to an understanding of models that does not claim a straightforward coincidence of models with reality, nature or the world. Models are not just simplified representations of reality; they are images (imaginations) which we construct from our environment. We constantly build and reconstruct our environmental access by using 
many different instruments and tools proactively and interactively. And these instruments and tools in turn influence our ways of (re-)construction. This making-of is not always an act of creation: we also (and maybe mainly) use images (imaginations) made by others, be those images maps, news articles, social network blogs, novels, theatre plays, etc. The use of images differs with respect to experience, social roles and positions, and many other contexts.

If this assumption of how reality can be accessed is true, then the role and meaning of models changes significantly. Models, then, are created, developed and applied in order to generate reality, not to represent it (although representation remains one, but only one, important characteristic). This approach is close to what Knuuttila (2006: 53) proposes: 'Rather than being representations in themselves, models are often valued for the results they produce.' The models are thus separate from an assumed objective, true or total reality which has to be imitated by applying certain sets of rules. They establish a kind of independence and autonomy. Laboratory experiments are sometimes characterized by a 'deep material similarity' between the target and the object used (Guala, 2002; Morgan, 2003), a similarity which is often ignored in simulation models. Winsberg (2009) questions this idea of a deep material similarity and advocates 'background knowledge' as the core distinction between experiment and simulation. I want to add that this background knowledge already rests upon one or more models to be used in conducting an experiment or a simulation (see also Saam, 2015: 73-74).

Models, moreover, reduce complexity in order to make the subject matter concretely tangible. Hence, it is not the unimaginable, opaque complexity addressed theoretically as 'reality' which is under investigation in models and computationally translated into quantities. The complexity of reality is a metaphor which acts as a counterpart to models, theories, quantifications. To compare this with system theory: we can conceive characteristics of systems, because they emerge as distinct objects, structurally and functionally. But initially, we are not able to talk about a system's environment - this environment is the other so-far unassigned side of the system.

If the aim of a model is not to represent or imitate the complexity of an unknown reality (see, for instance, Nipper (2011: 141) who claims that models shall 'represent reality as good as possible'), then a model embodies inherently its own justification by explicitly expressing its purpose, assumptions and ways of reducing complexity. This is quite similar to mapmaking by applying rules of generalization, or to statistical analysis by deliberately selecting variables and techniques in order to achieve a certain result.

Models are thus a distinctive way of creating an experimental system to make 'epistemic objects' visible and tractable, as Rheinberger (2001: 8) proposes. He defines 'epistemic objects' as 'things which embody notions' (ibid.: 15; translation A.K.). From a social geographical perspective, 'objects' such as injustice, inequality, poverty or segregation may be perceived as epistemic when associated with a spatial fixing (see Dorling, 2011). Dorling (2012) and Hennig (2013) provide impressive examples of making social-spatial injustice visible by applying cartograms and other quantitative tools. Rheinberger's intention is to avoid theory as the primary angle in research and putting experimental systems into the foreground. My aim is to avoid absolute external reality as a reference in modelling, foregrounding instead the inherent purposes, assumptions, framing conditions, parameter 
settings, etc. In doing this, I implement a realization of a modelling epistemology that has been claimed by several researchers. Among these are Epstein (2006), who argues for a 'generative social science' which allows the phenomenon of interest to grow in a simulation model of interacting agents, and Küppers et al. (2006), who equate simulation models epistemologically with a 'pragmatic construction of reality', whereby reality emerges inside the models (see also Edmonds and Meyer, 2013).

Instead of 'reality', it would therefore be more appropriate to refer to 'originals' which are being generated and represented by models. Originals refer to other originals, and in doing so there is no need to refer to an absolute truth/reality. This is in line with Stachowiak's (1973) General Model Theory, in which models are defined by three characteristics: (1) a model is always a representation of a natural or artificial original, and the original can itself be an original; (2) a model does not encompass all attributes of an original, but only those which seem to be relevant for the purposes of the model; (3) a model does not conflate with the original inherently, but depends on the purpose.

One example that takes the three characteristics of models epistemologically into consideration is given with maps that explicitly refer to the 'modifiable areal unit problem' (MAUP) of a scale- and zonal-dependent variation of statistical results. This is a common methodological and theoretical problem with both scientific and practical meaning which calls for the insertion of modifiable 'temporal units' and 'social units' (Koch and Carson, 2012). MAUP is also well established in geographical-methodological research (see, e.g., Openshaw, 1981), in which solutions or suggestions include Geographically Weighted Regression (Fotheringham et al., 2002; Ward and Gleditsch, 2008). The discursive and hermeneutical implications seem to be less obvious. As a variation of a statistical technique, it is likely with MAUP that the results depend crucially on the selected scale and the different size and shape of (mostly territorial) polygons. For example, for the same data set and spatial analysis, applying different measures of similarity and cluster-creation procedures in a cluster analysis investigation will lead to different results. A common phenomenon is an increase in homogenization through aggregation. 'This leads to some ambiguity. During the conversion of individuals to spatial units aggregation transforms the observed phenomenon completely. Although it is not always obvious, one should be aware that all kinds of aggregation are a transformation in the quality of information, even if it is but a small step from one spatial scale to the next' (Madelin et al., 2009: 647 (translation A.K.); see also Belina and Miggelbrink, 2010: 23). Hermann (2009: 703-04), in his study of correlations between 'individualization' and 'social status' in Switzerland, concludes that there is a positive correlation at canton level, but any correlation dissolves at the municipal level. Csillag and Agnew (1995: 104), using various approaches to regionalization, draw a similar conclusion in their investigation of election results in Italy: 'Perhaps the most important conclusion of this comparison of electoral regionalizations is that there is no clear "winner". Geographical regionalization is a complex task involving the weighting of different criteria of "goodness". If internal homogeneity and boundary contrast are given equal weight then we can reach a certain outcome, but if another weighting is desired then the choice might be different.'

A similar problem arises with boundary effects (zoning) when changing the shape of areas (while keeping the scale unaltered). Although there are valid political reasons for adapting borders, e.g. in spatial planning and the constitution of electoral constituencies, the choice of 
a particular bordering concept remains a problem with respect to the interpretation of results and must thus be made transparent and explicit. Concepts of bordering occasionally imply an uncritical dealing with multilevel spatial models. 'One of the criticisms of multilevel models, however, is that context is often unquestionably defined by the hierarchical structure of the available data' (Zolnik, 2009: 342). It is the purpose of the model that should determine the choice of an adequate spatial bordering concept, which in turn prevents an objective and unbiased interpretation of spatial-statistical results. Focusing on the relationship between the EU-funding policy and the NUTS-based spatial ordering of EU member states, Madelin et al. (2009: 651) conclude: 'The selection of the spatial reference unit is not an unbiased fact, and one can assume that some states have chosen greater or smaller area units for the selection of their NUTS-ordering in a deliberate manner' (translation A.K.). In other words, although these problems (MAUP, zoning, scaling) refer, by and large, to the methodological domain, they simultaneously imply effects on the conceptual and epistemological domain, because the design, content and results of a model may vary and thus may change our perception and comprehension of the world view.

\section{An example: modelling social-spatial segregation}

Three aspects have been outlined in this paper so far: (1) a diversity in the means of accessing and perceiving our environment; (2) a model-driven approach in reasoning about our environment; (3) a scale-dependent variation of results. Through translations and transformations, we can link all three domains to each other and try to develop models which incorporate them. One well-known phenomenon in this respect is the idea of emergence. In the area of social geography, emergence can be observed when individual motives at a local level are linked with social-spatial behaviour at a global level ('global' is used here as a relative term and refers to the model's overall purpose). Following Schelling (1971, 1969) regarding patterns of segregation in highly abstract conceptual spaces, it can be stated that processes of emergence that use simple local neighbourhood rules can affect the distribution of individual agents at the macro level in an unexpected way. In other words, the macro pattern result cannot be derived straightforwardly from the local neighbourhood rules (see, e.g., Crooks, 2008; Ioannides, 2013; Pancs and Vriend, 2009; with respect to complexity theory, see Manson et al., 2012).

Figure 1 illustrates the result of a simulation run [of a segregation model?] for a single variable with a binary difference (shown in red and green) for two populations of agents: the populations evaluated their immediate neighbourhood with respect to a preference (or not) for their own social group.

If a neighbourhood's ratio of red and green agents falls below a certain threshold, then the agents are dissatisfied and move to another place, repeating the evaluation in this new area. It is remarkable that, contrary to the individual aim of having $30 \%$ of neighbours in the same social group as their own (in the simulation case in Figure 1), the actual segregation is much higher in most areas, which was not intended by any single agent. 


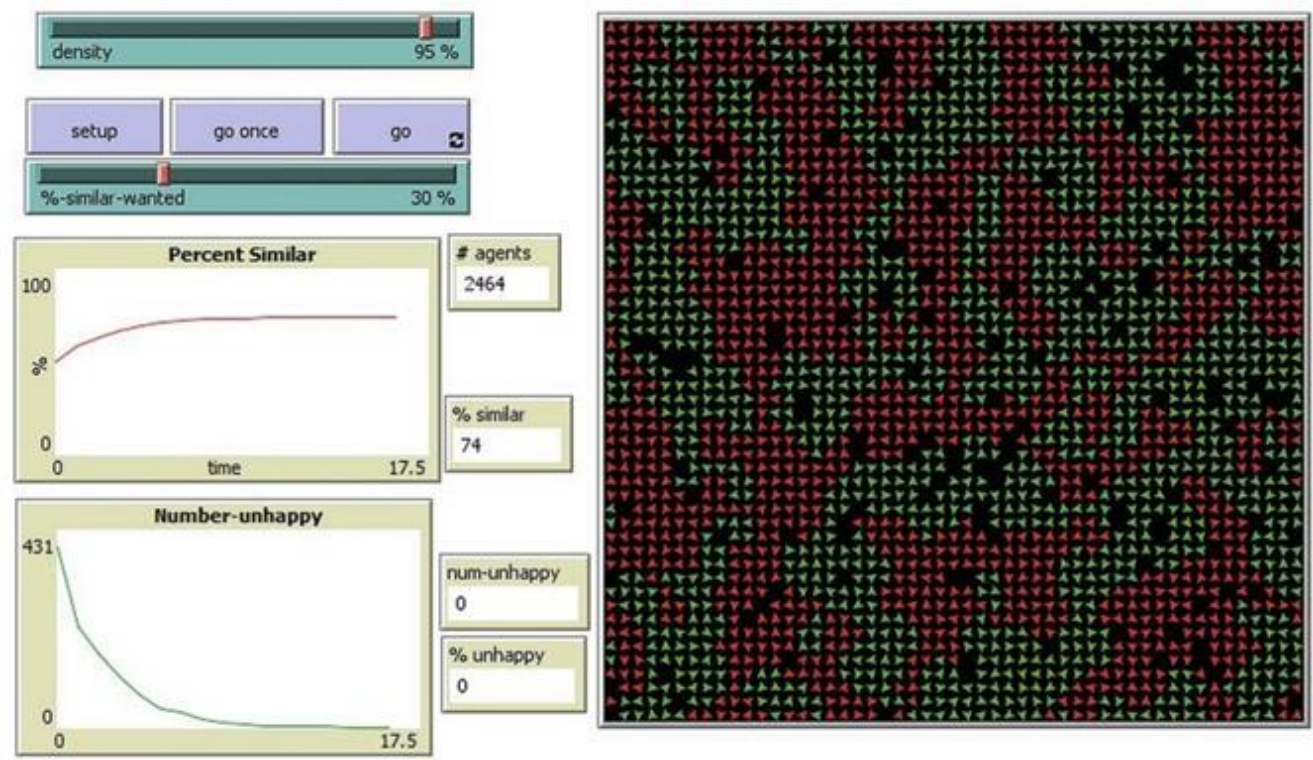

Figure 1: Simulation run of a Schelling-type segregation model in NetLogo (source: Wilensky, 1999)

This approach is based on inductive modelling without an explicit segregation theory. There are numerous theories which may help understand the basic principles of growing social homogeneity - among others, theories of social interactions which focus on strong ties (Granovetter, 1973; Squazzoni, 2012; Metcalf, 2014), theories based on endogenous, exogenous, and correlated effects (Ioannides, 2013), theories referring to households' hedonic behaviour and rent seeking housing markets (Waddell, 1997), econometric theories of land prices and land uses (Filatova et al., 2009), and, last but not least, planning theories like central-place theory (Christaller, 1933) or social housing policies (Dangschat, 1998). However, the Schelling-type segregation model and its contemporary derivations are first and foremost hypothesis-driven empirical models, which take into account observations from (large) cities around the world. Its explanatory character therefore makes this model type attractive for applied research in the field.

Models inevitably imply a reduction of the complexity of an imagined original. All scientific efforts of reasoning, explanation and comprehension are thus constructive and selective. The relationship between independence and interdependence is in constant transformation: 'Many individuals determine market events, and markets determine what happens in the heads and hearts of many individuals. It is, however, an individualistic ideology to believe that many individuals would be able to determine the "nature" of markets, societies or civilization exclusively by their will. The problem of this thinking is grounded in the phrase "we all as many individuals". How can a "we" emerge from many "I's" and generate effects that are completely different from a set of single actions?' (Hampe, 2011: 278; translation A.K.). On the other hand, subjective assessing is continuously influenced by a social 'we', because 'individuals are repeatedly exposed to socially biased sets of stimuli' (Eagles, 1995: 10). 


\section{$7 \quad$ Models as instruments and the risk of instrumentalization}

The relationships between contexts, presuppositions, multi-methodological approaches, reductionism and transformational perspectives quite often exhibit tensions because one or more of these elements was neglected and/or not explicitly applied. If this happens, then models, numbers or analytical results tend to be used as ideology. The model becomes a fetish, an independent and self-referential object. Remarkably, even if it explicitly and visibly includes all these relationships, the model becomes an independent object, because it specifically offers a single way to describe and explain reality. However, the model loses its fetish character. Belina and Miggelbrink (2010: 13) point to this problem for space-based comparisons: 'The compared subjects, $[\ldots]$, rights and discourses, cities and regions or territories are going to be cut off from the process of their creation through the comparisons - and thus cut off from all conflicts, struggles and contradictions which trigger them' (translation A.K.). If the premises of a model cannot be derived from the results, then it is likely that the risk of blind generalization and over-simplification is actually happening.

Without relationships and associations, models and numbers tend to be used as ideology or meer instruments. They become stylized facts, and the images (imaginations) they produce induce a kind of necessity, i.e., something that contradicts not being. A regional disparity, a poverty threshold or a correlation between voter turnout and social status is equated with reality, even if none of the parameters represents a single case. A related problem is given with the use of the notion of 'optimization' - model optimization is often equated with empirical optimization, confusing the purpose of the model with its premise.

Complementary to the ideologization of models, we have to take ideologization through models into account. Members of a social community or milieu potentially identify with scientific and political model results or analyses, whether these confirm their opinions, dismiss them or fall somewhere between the two. Mechanisms of self- and external exclusion are one of the most negative and sustainable effects of stigmatized identification. Quantifications of social life may, at specific scales, result in an image of social-spatial homogeneity. Gentrification can be seen as a good example of this. Theoretically understood as a repeated process of invasion and succession (whoever the term 'invasion' is actually used for), which commonly implies displacement of less affluent people and thus the growing socio-demographic homogeneity of a local neighbourhood, gentrification is empirically evident in many large cities worldwide. However, it is - simultaneously - a socially and spatially rather diverse phenomenon with many different manifestations. 'Setting ethnic minorities on a par with other pioneers is misleading, because the latter (students, artists, trainees) are equipped to a much higher degree with legitimate social capital, according to Bourdieu $[\ldots]$, than, for example, migrants or members of the working class' (Baumgärtner, 2009: 66; translation A.K.). 


\section{The problem is not to model the world, but how to deal with the modelled world}

Transparency and a clearer explication of the model's purpose and its premises offer greater freedom of analysis and more broadly applicable conclusions. Comparisons, the creation of hypotheses and scenarios, conducting experiments or the recognition of patterns cannot, any of them, avoid the precision and concreteness which are provided with quantification. The problem is not to model the world, but how to deal with the modelled world. Ideology and instrumentalization do not necessarily disappear with transparency and explication of intention. Precision and concreteness become conflated with contingency and compromise.

It would also be naïve and shortsighted to believe that other scientific approaches qualitative or narrative techniques - would not be threatened by ideologization or instrumentalization, as is the case for discourse theories (see, e.g., Foucault, 2011; Habermas, 1995; Lyotard, 2006) or neo-pragmatism (see, e.g., Putnam, 2007; Rorty, 1981). The construction and reconstruction of regional disparities and social stigmatization, as mentioned above, may serve as pithy examples.

\section{A plea for a critical quantitative geography and a quantitative critical theory}

In the light of quantitative and critical geography, two special issues of Professional Geographer of the Association of American Geographers (AAG) have been published with the programmatic title 'Quantitative Revolution 2: The Critical (Re)Turn' (Kwan and Schwanen, 2009). The strengths of a critical quantitative geography have been stressed by several authors who have given indications about the importance of context and the limitations of this kind of "doing" geography. "Quantitative geography is a powerful tool for challenging social and global injustice, and can play an important role in progressive social and political change' (ibid: 289). It can play this role because it acknowledges new epistemological knowledge methodologically. 'It now aligns more closely with certain premises of critical geographies than the kind of quantitative geography conceived during the quantitative revolution - for instance, its emphasis on local context and local relationships instead of global generalizations about spatial processes, its increased sensitivity to multiple axes of difference (e.g. gender, race, ethnicity, sexuality, and age), and its attention to processes through which individual spatial knowledge is constituted' (ibid: 284). In addition, the development of (geo-)statistical analytical techniques like geographically weighted regression (GWR, see above) or of simulation models like agent-based models or system dynamics approaches is moving the field towards the topics postulated above.

These developments might be influenced by the fact that translating a model's purpose and premises into a software tool (e.g. a Geographical Information System (GIS) or a simulation software tool) requires an a priori fixing definition of the modelling steps, and with it a decision about scales and the nature of reduction (at a meta level, the ODD paradigm Overview, Design concepts, Details - is important; see Grimm et al., 2013). Moreover, translations of notions commonly used within quantitative and critical geography have to be 
proved with respect to adequacy and reliability. ' [] mportant notions central to both critical and quantitative geography can be used to reconnect critical and quantitative geographies. The notions of difference and context, for instance, are two such connective constructs that can stimulate dialogue and enhance mutual understanding, even though - or perhaps exactly because - their conceptualizations in critical theory and spatial analysis differ in various ways [...]' (Kwan and Schwanen, 2009: 288).

Models and quantities generate and specify context thanks to its inherently concrete nature. This allows for visualization of spatial structures, functions and processes across multiple spatio-temporal scales, as Ellis (2009: 305) also emphasizes, without denying the difficulties of such an endeavour: 'With no census and other survey data on race, the material stratification of society by race would not fade, but it would become much harder to see at a structural, systemic level. [...] The act of collecting data by these fixed categories [of racial classification], of counting and estimating populations in them, reifies race and misleads with respect to the porosity of group boundaries and the variability of group experience.' Modelling by way of descriptive and narrative representations of originals is also not immune to charges of reification; reification is a general part of the methodological denominator: “'Fact” became fact became law became reality' (Wyly, 2009: 312).

A derived problem is data-driven reasoning, not because of the pragmatic relation between data availability and model adaptation, but because of a reversal of means and purpose - data justify the model's purpose and thus the claim of representing the truth. Context, too, remains important in methodological reasoning, and there is always a mutuality between empiricism and theory, between induction and deduction. 'Properly specified statistical models do nothing more than account for a quantity of the variance in an outcome of interest. In so doing, they are a representation [...] of a priori theorized causal relationships; they are never a substitute for this theorizing' (Ellis, 2009: 306). And to some degree theory targets empirical and experimental research.

All kinds of contextualization increase differentiation and the complexities of research settings, epistemological perspectives, and aspirations for valid interpretations. This leads to higher degrees of specialization and a more modest claim of explanation. In quantitative spatial analysis, the sophistication of statistical tools is continuously growing (Kwan and Schwanen, 2009: 284), which enables tailored models and tailored foci. Their growing sophistication means that quantitative techniques are increasingly suitable for approaching complexity. This has been appreciated by two critical female geographers: 'All statistics are social constructions, but when critical geographers abandon statistics, we give up the opportunity to shape and mobilize these constructions for progressive purposes. Our unilateral disarmament allows the socially constructed world of measurement to become more conservative, more ignorant of geography, and usually both. We give up the chance to construct certain things of facts - certain things done' (Wyly, 2009: 316). And Peake (2008: 9) endorses: 'I believe we are in danger of producing a whole generation of feminist geographers - and not just feminist geographers - who not only have no interest in quantitative techniques, but also have no training in how and when (or not) to use them, cutting off from enquiry and analysis a wide swathe of policy-based and applied research.' 


\section{Conclusion}

The basic purpose of this paper was to establish an understanding of models and quantitative approaches which stresses their adequateness in social scientific reasoning thanks to their characteristics in dealing with the subjects that matter. It has been argued that numbers, quantifications and models do not refer to an absolute truth or reality; that they do not represent or imitate reality, but create their own reality and impact by their application within scientific communities. Or as Ihde (2006: 84) argues with respect to imaginative techniques: '[]maging in the context of simulation and modeling is more analogous to a critical, interpretative instrument, through which we see and read. [...]. There is no original from which to copy. Yet the end result is image-like; it is a gestalted pattern which is recognizable, although it is a constructed image.'

Instead, models and numbers attempt to render tractable, graspable and visible those phenomena that we observe empirically or deduce theoretically. Since many social processes designed by models cannot be perceived straightforwardly or are unobservable in principle, it is the (communicative) relationship between model builders and model users that attributes their use, which is more important than looking for and looking at an intangible truth. 'Occam's razor may still be the ultimate quest, but in many social systems, evident complexity is so great that plausibility rather than validity may be the real quest' (Batty, 2012: 48).

If we accept this conclusion as plausible and convincing in modelling and quantification, we can reject assumptions that insinuate that quantifications are always reductions of a versatile reality and thus hamper diversity. This is so because, even though reduction is inevitable, modelling and quantification provide us with a necessary condition to create these versatile realities.

Statistical spatial analysis, modelling, simulation - all play a crucial role in helping us to structure our world, to orientate and navigate through the complexities that surround us. (A comprehensive confirmation of this appraisal can be found in Heppenstall et al., 2012.) Although models are not synonymous with theories for several reasons, they are not as different as Derman (2011) would have us believe. While it may be plausible to associate theory with 'stated facts' and models with 'assumed facts', the statement that '[the] role of theory is to make evident what is hidden' (ibid: 60) can be ascribed to models as well. Moreover, models and theories merge in the process of uncovering invisible principles. Models and theories do simplify, which is contrary to the position of Derman, who states: 'A theory does not simplify' (ibid.); both are inherently partial, scaled, temporal, selective and translated (see Nagel, 2012). Models, numbers and quantitative methods are thus necessary and therefore something that does contradict not to be. 


\section{References}

Batty M. (1995). Geographic information systems in the social and policy sciences. In Eagles, M. (ed.), Spatial and Contextual Models in Political Research. London: Routledge, pp. 15-40.

Batty M. (2012). A Generic Framework for Computational Spatial Modelling. In Heppenstall A. J., Crooks A. T., See L. M., Batty M. (eds.) (2012), Agent-Based Models of Geographical Systems. Dordrecht, Heidelberg, London, New York: Springer, pp. 19-50.

Baumgärtner E. (2009). Lokalität und kulturelle Heterogenität. Selbstverortung und Identität in der multi-ethnischen Stadt. Bielefeld: Transcript.

Belina B., Miggelbrink J. (2010). Hier so, dort anders. Zum Vergleich von Raumeinheiten in der Wissenschaft und anderswo - Einleitung zum Sammelband. In Belina B., Miggelbrink J. (Hrsg.) (2010), Hier so, dort anders. Zum Vergleich von Raumeinheiten in der Wissenschaft und anderswo. Münster: Westfälisches Dampfboot, pp. 7-39.

Bourdieu P., Wacquant L. (1996). Reflexive Anthropologie. Frankfurt a.M: Springer.

Christaller W. (1933). Die zentralen Orte in Süddeutschland. Eine ökonomisch-geographische Untersuchung über die Gesetzmäßigkeit der Verbreitung und Entwicklung der Siedlungen mit städtischer Funktion. Darmstadt 1980, (Repr. d. Ausg. Jena 1933).

Christie M., Cliffe A., Dawid P., Senn S. (2011). Simplicity, Complexity and Modelling. Chichester: Wiley \& Sons.

Cremer G. (2016). Armut in Deutschland. München: C. H. Beck.

Crooks A. (2008). Constructing and Implementing an Agent-Based Model of Residential Segregation through Vector GIS. UCL Working Papers Series, Paper 133.

Csillag F., Agnew J. (1995). How many Italies? A strategy for spatial analysis of regionalizations of Italian election results, 1953-87. In Eagles, M. (ed.): Spatial and Contextual Models in Political Research. London: Taylor \& Francis, pp. 85-105.

Dangschat J. (1998). Warum ziehen sich Gegensätze nicht an? Zu einer Mikro-Meso-Makro-Theorie ethnischer und rassistischer Konflikte im städtischen Raum. In May M., Alisch M. (Hrsg.) (2012): Formen sozialräumlicher Segregation. Berlin, Toronto: Opladen, pp. 23-50.

Derman E. (2011). Models.Behaving.Badly. New York, London, Toronto, Sydney, New Delhi: Free Press.

Dorling D. (2011). Injustice. Why Social Inequality Persists. Bristol: Policy Press.

Dorling D. (2012). The Visualization of Spatial Social Structure. Chichester: Wiley \& Sons.

Eagles M. (1995). Spatial and contextual models in political research: an introduction. In Eagles M. (ed.): Spatial and Contextual Models in Political Research. London: Taylor \& Francis, pp. 3-14.

Edmonds B., Meyer R. (eds.) (2013). Simulating Social Complexity. Heidelberg, New York, Dordrecht, London: Springer.

Ellis M. (2009). Vital Statistics. The Professional Geographer, 61(3), pp. 301-309.

Epstein J. M. (2006). Generative Social Science. Studies in Agent-Based Computational Modeling. Princeton and Oxford: Princeton University Press.

Filatova T., Parker D., van der Veen A. (2009). Agent-Based Urban Land Markets: Agent's Pricing Behavior, Land Prices and Urban Land Use Change. Journal of Artificial Societies and Social Simulation, Vol. 12, No. 1, http://jasss.soc.surrey.ac.uk/12/1/3.html (2018-01-28).

Fotheringham A.S., Charlton M., Brunsdon C. (2002). Geographically weighted regression: The analysis of spatially varying relationships. New York: Wiley.

Foucault M. (2011). Die Ordnung des Diskurses, 11. Auflage, Frankfurt a.M.: Fischer.

Geertz C. (1993). Local Knowledge. London: Fontana Press.

Granovetter M. S. (1973). The Strength of Weak Ties. American Journal of Sociology, Vol. 78, Issue 6, pp. 1360-1380. 
Grimm V., Polhill G., Touza J. (2013). Documenting Social Simulation Models: The ODD Protocol as a Standard. In Edmonds B., Meyer R. (eds.): Simulating Social Complexity. Heidelberg: Springer, pp. 117-133.

Guala F. (2002). Models, Simulations, and Experiments. In Magnani L., Nersessian N. (eds.), Modelbased reasoning: Science, Technology, Value. New York: Kluwer, pp. 59-74.

Habermas J. (1995). Theorie des kommunikativen Handelns (2 Bände), 8. Auflage, Frankfurt a.M.: Suhrkamp.

Hampe M. (2011). Tunguska oder Das Ende der Natur. München: Hanser.

Hennig B. (2013). Rediscovering the World. Map Transformations of Human and Physical Space. Dordrecht, Heidelberg, London, New York: Springer.

Heppenstall A. J., Crooks A. T., See L. M., Batty M. (eds.) (2012). Agent-Based Models of Geographical Systems. Dordrecht, Heidelberg, London, New York: Springer.

Hermann M. (2009). Kartographie sozialräumlicher Zusammenhänge. Informationen zur Raumentwicklung, Heft 10/11, pp. 701-709.

Ihde D. (2006). Models, Models Everywhere. In Lenhard J., Küppers G., Shinn T. (eds.): Simulation. Pragmatic Construction of Reality. Dordrecht: Springer, pp. 79-86.

Ioannides Y. (2013). From Neighborhoods to Nations. The Economics of Social Interaction. Princeton: Princeton University Press.

Kamper D. (1996). Je mehr Zufall, desto mehr Spiel. In Hammel E. (Hrsg.): Synthetische Welten. Kunst, Künstlichkeit und Kommunikationsmedien. Essen: Die Blaue Eule, pp. 109-117.

Knuuttila T. (2006). From Representation to Production: Parsers and Parsing in Language Technology. In Lenhard J., Küppers G., Shinn T. (eds.), Simulation. Pragmatic Construction of Reality. Dordrecht: Springer, pp. 41-55.

Koch A. (2013). Lokales Armutswissen und regionale Disparitäten. In Gaisbauer H., Kapferer E., Koch A., Sedmak C. (Hrsg.): Armut und Wissen. Reproduktion und Linderung von Armut in Schule und Wissenschaft. Bielefeld: Springer VS, pp. 225-246.

Koch A., Carson D. (2012). Spatial, Temporal and Social Scaling in Sparsely Populated Areas geospatial mapping and simulation techniques to investigate social diversity. In Car A., Griesebner G., Strobl J. (Hrsg.): Geospatial Crossroads @ GI_Forum '12, Proceedings of the Geoinformatics Forum Salzburg, Offenbach, pp. 44-53.

Küppers G., Lenhard J., Shinn T. (2006). Computer Simulation: Practice, Epistemology, and Social Dynamics. In Lenhard J., Küppers G., Shinn T. (eds.): Simulation. Pragmatic Construction of Reality. Dordrecht: Springer, pp. 3-22.

Kwan M.-P., Schwanen T. (2009). Quantitative Revolution 2: The Critical (Re)Turn. The Professional Geographer, 61(3), pp. 281-291.

Lepenies P. (2017). Armut. Ursachen, Formen, Auswege. München: C. H. Beck.

Lewin K. (1931). The Conflict between Aristotelian and Galileian Modes of Thought in Contemporary Psychology. Journal of General Psychology, 5, pp. 141-177.

Link O. (2011). 'Die Welt lässt sich nicht berechnen'. brand eins, 13. Jg., Heft 11, pp. 110-115.

Lotter W. (2011). Wir rechnen mit allem. brand eins, 13. Jg., Heft 11, pp. 40-54.

Lyotard F. (2006). Das postmoderne Wissen. 5. Auflage, Wien: Passagen Verlag.

Madelin M., Grasland C., Mathian H., Sanders L., Vincent J.-M. (2009). Das 'MAUP': Modifiable Areal Unit - Problem oder Fortschritt? Informationen zur Raumentwicklung, Heft 10/11, pp. 645-660.

Manson S. M., Sun S., Bonsal D. (2012). Agent-Based Modeling and Complexity. In Heppenstall A. J., Crooks A. T., See L. M., Batty M. (eds.) (2012): Agent-Based Models of Geographical Systems. Dordrecht, Heidelberg, London, New York: Springer, pp. 125-139.

Maretzke S. (2006). Regionale Disparitäten - eine bleibende Herausforderung. Informationen zur Raumentwicklung, Heft 9, pp. 473-484.

Mau S. (2017). Das metrische Wir. Über die Quantifizierung des Sozialen. Berlin: Suhrkamp. 
Metcalf S. S. (2014). Modeling Social Ties and Household Mobility. Annals of the Association of American Geographers, Vol. 104, Number 1, pp. 40-59.

Morgan M. (2003). Experiments Without Material Intervention. Model Experiments, Virtual Experiments, and Virtually Experiments. In Radder H. (ed.), The Philosophy of Scientific Experimentation. Pittsburgh: University of Pittsburgh Press, pp. 216-235.

Nagel T. (2012). Mind and Cosmos: Why the Materialist Neo-Darwinian Conception of Nature is Almost Certainly False. Oxford: Oxford University Press.

Nipper J. (2011). Rechnen und Mathematikmachen: quantitative Analyseverfahren in der Geographie. In Gebhardt H., Glaser R., Radtke U., Reuber P. (Hrsg.): Geographie. 2. Auflage. Heidelberg: Springer.

Openshaw S. (1981). The modifiable areal unit problem. In Wrigley N., Bennet R.J. (eds.): Quantitative Geography: A British View. pp. 60-69.

Pancs R., Vriend N. J. (2007). Schelling's spatial proximity model of segregation revisited. Journal of Public Economics 91, pp. 1-24.

Peake L. (2008). Moving on up. Gender, Place, and Culture 15(1), pp. 7-10.

Putnam H. (2007). Pragmatism and Realism. London: Routledge.

Reckwitz A. (2017). Die Gesellschaft der Singularitäten. Berlin: Suhrkamp.

Rheinberger H.-J. (2001). Experimentalsysteme und epistemische Dinge. Eine Geschichte der Proteinsynthese im Reagenzglas. Göttingen: Wallstein.

Rorty R. (1981). Der Spiegel der Natur. Frankfurt a. M: Suhrkamp.

Rosanvallon P. (2013). Die Gesellschaft der Gleichen. Hamburg: Hamburger Edition HIS.

Saam N. J. (2015). Simulation in den Sozialwissenschaften. In Braun N. und Saam N. J. (Hrsg.). Handbuch Modellbildung und Simulation in den Sozialwissenschaften. Wiesbaden: Springer VS, pp. 61-95.

Schäfer L., Schnelle T. (Hrsg.) (2012). Ludwik Fleck. Entstehung und Entwicklung einer wissenschaftlichen Tatsache. 9. Auflage. Frankfurt a.M: Suhrkamp.

Schelling T. C. (1969). Models of segregation. American Economic Review, Papers and Proceedings 59, pp. 488-493.

Schelling T. C. (1971). Dynamic models of segregation. Journal of Mathematical Sociology 1 (2), pp. 143-186.

Schurz G. (2008). Einführung in die Wissenschaftstheorie. Darmstadt: Wissenschaftliche Buchgesellschaft.

Squazzoni F. (2012). Agent-Based Computational Sociology. Chichester: Wiley \& Sons.

Stachowiak (1973). Allgemeine Modelltheorie. Wien New York (Reprint): Springer.

Strubelt W. (2006). Auf der Suche nach der Gleichwertigkeit der Lebensverhältnisse - oder: Die Suche nach verloren gegangenem Sinn der Zeit? Informationen zur Raumentwicklung, Heft 9, pp. 305308.

Waddell P. A. (1997). Household Choice and Urban Structure. Aldershot: Ashgate.

Ward M. D., Gleditsch K. S. (2008). Spatial Regression Models. Los Angeles, London, New Delhi, Singapore: Sage.

Weiss W. (2010). Gödels Unvollständigkeitssatz, die Vernunft, Metawahrheit(en) und Everetts Vielweltentheorie. Wissenschaftliche Nachrichten des Bundesministeriums für Unterricht, Kunst und Kultur, pp. 3-12.

Wilensky U. (1999). NetLogo. http://ccl.northwestern.edu/netlogo/. Center for Connected Learning and Computer-Based Modeling, Northwestern University, Evanston, IL.

Winsberg E. (2009). A tale of two methods. Synthese 169, DOI 10.1007/s11229-008-9437-0, pp. 575592.

Wyly E. (2009). Strategic Positivism. The Professional Geographer, Vol. 61, No. 3, pp. 310-322.

Zolnik E. J. (2009). Context in Human Geography: A Multilevel Approach to Study Human-Environment Interactions. The Professional Geographer, Vol. 61, No. 3, pp. 336-349. 